\title{
POLÍTICA DAS COTAS RACIAIS E OS ALUNOS DO ENSINO MÉDIO DAS ESCOLAS PÚBLICAS DA REGIÃO DE ITAPETININGA
}

\section{ARTIGO ORIGINAL}

NASCIMENTO, Marcelo Victor Rodrigues do ${ }^{1}$

NASCIMENTO, Marcelo Victor Rodrigues do. Política das cotas raciais e os alunos do ensino médio das escolas públicas da região de Itapetininga. Revista Científica Multidisciplinar Núcleo do Conhecimento. Ano 05, Ed. 01, Vol. 08, pp. 4973. Janeiro de 2020. ISSN: 2448-0959, Link de acesso: https://www.nucleodoconhecimento.com.br/ciencias-sociais/politica-das$\underline{\text { cotas }}$

\section{RESUMO}

Este trabalho teve por objetivo verificar qual o grau de ciência dos alunos do ensino médio da região de Itapetininga, a respeito da política de cotas empreendida pelo Governo Federal, suas opiniões acerca do racismo e se eles têm participado de debates e outras "ações afirmativas" tanto na escola quanto no município, que thes permitam refletir acerca das questões raciais envolvendo os afro-descendentes. Para tanto, foram entrevistados 192 alunos do ensino médio público, que estudam na área da Diretoria de Ensino - Região de Itapetininga, da Secretaria da Educação do Estado de São Paulo. Na entrevista, foi abordada (1) a ciência dos alunos acerca da existência da "lei das cotas"; (2) o racismo no Brasil; (3) a realização de debates e

\footnotetext{
${ }_{1}^{1}$ Doutor e Mestre em Teologia, pela Universidade da Bíblia. Especialista em Exercício Resistido na Saúde, na Doença e no Envelhecimento, pela Faculdade de Medicina da Universidade de São Paulo (USP). Pós-graduado em Magistério do Ensino Superior, pela Universidade Paulista (UNIP). Bacharel em Ciências Militares pela Academia da Força Aérea Brasileira (AFA). Bacharel em Educação Física, pela Escola de Educação Física do Exército (EsEFEx). Bacharel em Administração de Empresas, pela Universidade Presbiteriana Mackenzie.
} 
ações relacionadas com os negros na escola e no município que residem; (4) o desporto capoeira e o currículo escolar; (5) a reserva de vagas para negros nas universidades e concursos públicos, e (6) a quantidade de afro-descendentes nas escolas da região. Os percentuais obtidos indicaram que (1) grande parte dos alunos nunca ouviu falar da Lei das Cotas, (2) todos sabem o que significa racismo e grande parte já presenciou situações que classificam como tal, (3) a grande maioria entende que a educação é o caminho para erradicar o racismo, mas poucos participaram de ações afirmativas culturais e educacionais na escola e município, (4) todos os alunos conhecem a capoeira, mas nem todos a querem no currículo escolar, (5) mais da metade dos entrevistados é contra a reserva de vagas para afro-descendentes nas universidade e concursos públicos e (6) a maioria declarou-se branco, apesar das pesquisas apontarem para a prevalência de mestiços no Brasil. Conclui-se que a deficiência da ação do poder público e das instituições de ensino públicas na região estudada é uma das grandes causas da ineficiência no combate ao preconceito racial no Brasil, fato que, além de estar prejudicando o desenvolvimento do senso crítico por parte dos alunos do ensino médio, contribui para perpetuar os modelos altamente racistas do passado, que condenaram milhares de pessoas a viverem na marginalidade.

Palavras-chave: racismo, lei das cotas, vagas, ensino superior, capoeira.

\section{INTRODUÇÃO}

Em busca do pagamento de uma suposta dívida com a raça negra e indígena e para a promoção da igualdade racial no Brasil, em 29 de agosto de 2012, foi aprovada a Lei 12.711, popularmente conhecida como "Lei das Cotas" que dispõe sobre o ingresso de autodeclarados pretos, pardos e indígenas e de pessoas com deficiência física nas universidades federais e nas instituições federais de ensino técnico de nível médio (Lei n. 12.711, 2012).

Tal lei, no entanto, veio apenas ratificar o que já ocorria nas universidades brasileiras desde 2003, quando a Universidade Estadual do Rio de Janeiro (UERJ) iniciou um "programa de cotas", que se estendeu a outras universidades, chegando a 14 
(catorze) universidades em 2005, a 43 (quarenta e três) em 2006 e a 83 (oitenta e três) em 2010 (Guarnieri e Melo-Silva, 2017).

Por isso, é possível depreender que, apesar de toda controvérsia existente acerca das cotas raciais, o programa de cotas no Brasil foi implementado antes mesmo de se tornar uma lei federal, sendo, portanto, um indicador de que aquele programa, iniciado em 2003, na UERJ, foi um sucesso, mesmo não sendo um consenso (Guarnieri et al, 2017).

Desde aquela época, diversas "ações afirmativas" (programas e medidas especiais que visam corrigir as desigualdades raciais e promover a igualdade de oportunidades) vêm sendo realizadas no Brasil, a fim de cumprir as determinações contidas na legislação em vigor e atingir os objetivos propostos (Ferreira e Mattos, 2007).

Em 2008, foi aprovada uma lei determinando que, nos estabelecimentos de ensino fundamental e de ensino médio, públicos e privados, seria obrigatório o estudo da história e cultura afro-brasileira e indígena (Lei n. 11.645, 2008).

Dois anos depois, em 2010, o Governo Federal institui o Sistema Nacional de promoção da Igualdade Racial (Sinapir), definindo, entre outras coisas, que seriam desenvolvidas campanhas educativas, inclusive nas escolas, para que a solidariedade aos membros da população negra fizesse parte da cultura de toda a sociedade. Além disso, a "capoeira" passaria à condição de desporto de criação nacional nos termos do artigo 217 da Constituição Federal, sendo facultado seu ensino nas instituições públicas e privadas, por capoeiristas e mestres tradicionais, pública e formalmente reconhecidos (Lei n. 12.288, 2010).

Quatro anos mais tarde, o Governo Federal determinou que 20\% (vinte por cento) das vagas oferecidas nos concursos públicos, a fim de prover os cargos efetivos e empregos públicos, no âmbito da administração pública federal, das autarquias, das fundações públicas, das empresas públicas e das sociedades de economia mista controladas pela União, seria destinada aos autodeclarados pretos ou pardos, 
conforme a classificação de cor ou raça definido pela Fundação Instituto Brasileiro de Geografia e Estatística (Lei n. 12.990, 2014).

Contudo, embora salutares do ponto de vista das "ações afirmativas", tais mudanças, de acordo com Ferreira et al (2007), acabaram por tocar un passant em um aspecto muito mais profundo: a identidade do afro-descendente, construída (como no caso de qualquer pessoa) a partir de suas condições de vida, tanto no que se refere à imagem de si próprio, quanto à imagem estabelecida pela sociedade para tal grupo de pessoas.

Tais autores sugerem que, para uma efetiva mudança, são necessárias "situações de impacto" que neguem as identidades culturais, gerando momentos de crise, de forma a impelir tanto negros quanto brancos a repensarem seus valores e mudarem suas concepções e subjetividades (Ferreira et al., 2007).

Os debates parecem ser boas situações de crise, onde os envolvidos são impelidos a penetrarem do âmago das questões, reorganizando suas ideias e revendo seus conceitos. Para os negros, em particular, parecem ser boas oportunidades para romperem com a ideia de que as diferenças são naturais e para refletirem sobre quem foram os seus antepassados, quais são as suas condições atuais e o que desejam para os dias vindouros, tanto para si quanto para seus descendentes (Ferreira et al., 2007).

A escola é indubitavelmente o espaço mais apropriado para se promover debates acerca dos assuntos de interesse nacional, como o racismo, por exemplo, pois, além da curiosidade natural da juventude, depois da convivência familiar, é o grupo social onde crianças e jovens tem contacto com o "diferente", ou seja, com pessoas de diferentes religiões, padrões sociais, cor, cultura, etc. (Silva e Ferreira, 2014).

Segundo a Lei de Diretrizes e Bases da Educação (LDB), é no Ensino Médio que os alunos devem ser estimulados a desenvolver o pensamento crítico e a se preparar para o exercício da cidadania, tornando tal fase (do desenvolvimento humano) a mais propícia para as discussões acerca de temas controversos, como a Lei da Cotas por 
exemplo (Lei no 9.394, 1996). Além do que, os alunos do ensino médio estão às portas do ensino superior, sendo impactados diretamente por essa ação afirmativa do Governo Federal.

Dentro dessa ótica, esta pesquisa científica tem por objetivo verificar qual o grau de ciência dos alunos do ensino médio da região de Itapetininga - SP a respeito da política de cotas empreendida pelo Governo Federal, suas opiniões acerca do racismo e se eles têm participado de debates e outras "ações afirmativas", tanto na escola quanto no município, que lhes permitam refletir acerca das questões raciais envolvendo os afro-descendentes.

\section{METODOLOGIA}

Conforme definições de Cervo e Bervian (1983), esta pesquisa pode ser classificada como um estudo descritivo e transversal, destinado a observar, registrar, analisar e correlacionar fenômenos (variáveis), sem manipulá-los, ocorridos em um dado momento com um público específico.

$O$ instrumento de coleta foi um questionário elaborado pelo autor (Apêndice $A$ ), contendo 1(uma) pergunta aberta, 3 (três) perguntas mistas, 13 (treze) perguntas fechadas, sendo que, destas, 2 (duas) são de múltipla escolha e 11 (onze) são do tipo dicotômica, ou seja, que verifica a concordância ou discordância do entrevistado acerca de determinada afirmação favorável ou desfavorável em relação ao objeto da pesquisa (Vieira, 2010; Ribeiro et al. 2016).

As perguntas tiveram como base o Estatuto da Igualdade Racial (Lei n. 12.288, 2010) e abordaram os seguintes aspectos da lei:

- O racismo, como algo que deve ser combatido (Art. $1^{\circ}$ );

- Os debates sobre preconceito racial nas instituições de ensino e sociedade, como algo que deve ser incentivado e patrocinado pelo poder público (Art. 11º);

- O desporto capoeira, de matriz negra, como um bem de natureza imaterial e de formação da identidade cultural brasileira (Art. $20^{\circ}, 21^{\circ}$ e $22^{\circ}$ ); 
- O acesso dos negros ao ensino superior, como uma ação afirmativa voltada para promover a igualdade de oportunidade e inclusão social (Art. 56º).

Inicialmente, o questionário investigou o conhecimento e a compreensão dos entrevistados acerca do tema da pesquisa, a Lei das Cotas, bem como a origem de tal conhecimento. Em seguida, foi tratado do tema racismo, sua compreensão e existência concreta nos dias atuais, tendo como base o universo dos alunos.

Na sequência, o questionário abordou a questão da realização ou não de debates e ações voltadas para o combate ao preconceito racial, tanto na escola quanto no município do entrevistado. Depois, questionou-se sobre o conhecimento ou não da "capoeira", um desporto de matriz africana, e de sua aceitação como parte do currículo escolar.

Mais à frente, foi solicitada a opinião do entrevistado acerca de ações que poderiam ser tomadas contra o preconceito racial e finalizou-se o questionário com dois assuntos-chave: 0 acesso dos negros à universidade pública mediante cotas raciais $\mathrm{e}$ a classificação que o próprio entrevistado faz da cor da sua pele.

A quantificação do número de afro-descendentes entre os alunos entrevistados, objetivou obter um retrato da realidade escolar da região investigada, sabendo-se, de antemão, que o grau de escolaridade é algo historicamente excludente com relação aos negros no Brasil (Chemim, 2013).

$\mathrm{Na}$ relação das cores apresentada aos entrevistados, para que ele apontasse a cor da sua pele, foi trocada propositalmente a classificação "parda" (classificação oficialmente definida pelo Instituto Brasileiro de Geografia e Estatística como intermediária entre o branco e o negro) pela classificação "morena", em virtude desta se tratar de uma expressão mais popular, tida psicologicamente como menos agressiva e menos polarizada, tornando mais favorável a aceitação da própria cor como não branca (IBGE, 2008, p. 37, 65; Sansone, 2003, p. 75).

Contudo, o questionário trouxe a opção "outra", para os casos em que o entrevistado viesse a escolher, como cor da sua pele, a própria cor parda, ou outra classificação 
qualquer como "mulata", ou "mestiça", ou "escura", ou "morena clara", ou "morena escura", ou "ruiva", etc., classificações bastante comuns, conforme outras pesquisas do gênero (IBGE, 2008, p. 40; Sansone, 2003, p. 62).

\subsection{AMOSTRA}

A amostra analisada na investigação foi constituída de 192 alunos do ensino médio das escolas públicas estaduais, da área da Diretoria de Ensino - Região de Itapetininga, da Secretaria da Educação do Estado de São Paulo (Governo do Estado de São Paulo, 2019).

As pessoas da amostra foram recrutadas aleatoriamente, sem critérios específicos de sexo, cor, idade, ano letivo $\left(1^{\circ}, 2^{\circ}\right.$ ou $3^{\circ}$ anos do ensino médio), religião ou condição social, formando uma amostra aleatória simples segundo definição de Vieira (2011). Os alunos, após terem tomado conhecimento da pesquisa, manifestaram interesse em participar voluntariamente da mesma.

Quanto às instituições de ensino dos entrevistados, o pesquisador foi impedido de realizar as pesquisas no âmbito das escolas da rede pública em 2019, visto que a Diretoria Regional de Ensino da Região de Itapetininga respondeu negativamente (Anexo A) a um ofício de solicitação do pesquisador (Apêndice B), por causa das "demandas educacionais". Por isso, a pesquisa foi realizada diretamente com os alunos, fora do ambiente escolar.

\subsection{PROCEDIMENTOS}

O questionário foi impresso pelo autor da pesquisa e apresentado particularmente aos alunos, no período de 01 de outubro a 10 de dezembro de 2019, sem a participação das escolas estaduais da região de Itapetininga, os quais preencheram-no individualmente, sob a autoadministração e sem a interferência do entrevistador.

Os dados coletados nas perguntas fechadas e mistas formam tratados quantitativamente, empregando-se gráficos e variáveis estatísticas, tais como "percentual", "valor mínimo" e "valor máximo" (Medeiros, 2007). 
A pergunta aberta, por sua vez, foi analisada qualitativamente (conteúdo e semântica), considerando a situação vivenciada pelo entrevistado, de estudante de uma escola pública do interior do estado de São Paulo (Henkel, 2017; Martins, 2017).

\section{ANÁLISE E DISCUSSÃO DOS DADOS}

A Lei das Cotas, aprovada há 7 anos, vem se mostrando como um dos instrumentos mais eficazes para ampliar o acesso de afro-descendentes (negros e pardos) ao ensino superior no Brasil, segundo estatística do Instituto Nacional de Estudos e Pesquisas Educacionais (INEP, 2018). Porém, nem todos os alunos do ensino médio a conhecem, ainda que sejam os maiores interessados no assunto, exatamente por estarem às portas do ensino superior.

A Tabela 1 mostra que, dos 192 entrevistados, 44\% nunca ouviu falar da Lei das Cotas e, dos que ouviram falar (56\%), 12,8\% não sabem o que ela significa. Além disso, dentre os que declararam conhecer a Lei das Cotas, $49 \%$ deles afirmaram terem tomado conhecimento por outros meios que não a escola.

Isso revela que as instituições diretamente envolvidas no processo de criação de uma nova identidade para os afrodescendentes no Brasil (as escolas da região de Itapetininga), parecem não estar atentas às suas responsabilidades e importância para a consecução da políticas públicas do Governo Federal, com vistas a erradicar o preconceito racial no Brasil.

Tabela 1. Percentuais relativos ao conhecimento da Lei das Cotas.

Perguntas 1, 2 e 3 do questionário do Apêndice $A$

1. Você já ouviu falar na "Lei das Cotas" para negros?

56\% Sim $\quad 44 \%$ Não

2. Se você já ouviu falar na "Lei das Cotas" para negros, responda: onde ouviu falar? (obs: caso não tenha ouvido falar, não marque nenhuma resposta) $13 \%$ TV 
$51 \%$ Escola

$12 \%$ Entre amigos

$16 \%$ Internet

$5 \%$ Revistas/Jornais

$0 \%$ Evento

$3 \%$ Outro

3. Se você já ouviu falar na "Lei das Cotas" para negros, responda: sabe o que ela significa? (obs: se nunca ouviu falar, não marque nenhuma resposta).

Fonte: do Autor (2019), com base no Questionário do Apêndice A.

Poder-se-ia afirmar que uma das causas da desinformação é o fato de que mais de um terço dos domicílios brasileiros não tem acesso à internet, especialmente das classes sociais $\mathrm{D}$ e $\mathrm{E}$, as quais fornecem a maioria dos alunos das escolas públicas (Mello, 2018). No entanto, pelo prazo da promulgação da referida lei (7 anos) e pela clareza da legislação quanto a participação direta do poder público e das instituições de ensino nesse processo, a ignorância é injustificável, ainda mais se for considerado o fato da pesquisa ter sido realizada no estado de São Paulo, o mais desenvolvido do país.

A ausência de tensões raciais no Brasil, ao contrário dos EUA, e a política de cordialidade racial iniciada na era do governo populista do presidente Getúlio Vargas fortalecem a ideia de que o Brasil vive uma democracia racial. No entanto, os números mostram exatamente o contrário, ou seja, que tal ideia não passa de uma ilusão (Sales Jr, 2006).

A Tabela 2 revela que: (1) a totalidade dos alunos entrevistados sabe perfeitamente 0 que significa racismo, (2) o preconceito racial é algo concreto na sociedade brasileira atual, e (3) grande parte já presenciou situações que classificam como racistas. Tal 
realidade parece contrariar o discurso que garante que a maioria das pessoas são contra o racismo e desejam que ele seja combatido e erradicado (Nunes, 2010).

São números preocupantes que merecem profunda reflexão por parte dos brasileiros, principalmente das instituições envolvidas diretamente com a formação moral, ética, intelectual e social dos jovens brasileiros.

Tabela 2. Percentuais relativos ao racismo.

Perguntas 4, 5 e 6 do Questionário do Apêndice A

4. Você sabe o que significa "racismo" (preconceito racial contra os negros)? $100 \% \operatorname{Sim}$

$0 \%$ Não

5. Você acha que existe "racismo" atualmente no Brasil?

\begin{tabular}{l|l}
$\mathbf{9 9 , 5} \%$ Sim & $\mathbf{0 , 5} \%$ Não
\end{tabular}

6. Você já presenciou alguma situação que chamaria de "racismo"? $78 \% \operatorname{Sim}$

$22 \%$ Não

\section{Fonte: do Autor (2019), com base no Questionário do Apêndice A.}

É muito provável que os jovens alunos não consigam distinguir as dimensões do racismo (ideológica, das atitudes e estrutural), não identificando, portanto, que, além do racismo declarado, existe ainda o racismo velado e sutil (Nunes, 2010; Campos, 2017). Por certo, se soubessem e reconhecessem os meandros do racismo, os índices da pesquisa seriam bem mais graves.

A literatura mostra que os debates são situações de impacto, que fazem com as pessoas sejam postas em cheque e reflitam melhor sobre suas concepções, levandoas, muitas das vezes, a conhecerem-se melhor e, no caso do racismo, por exemplo, a compreenderem que são racistas sem perceber (Ferreira et al., 2007; Nunes, 2010).

A Tabela 3 mostra que a imensa maioria dos alunos acredita que o debate é fundamental para promover reflexões profundas sobre o tema. Contudo, os dados mostram que, tanto a escola em que estudam, quanto o município em que vivem, parecem não ter compreendido a importância dessa realidade, ignorando grande parte 
das suas atribuições previstas na legislação em vigor, relacionadas à cultura e a educação (Lei no $12.288,2010$ ).

Tabela 3. Percentual relativo às ações afirmativas realizadas na escola e no município.

Perguntas 7, 8, 9 e 10 do questionário do Apêndice $A$

7. Você já participou na sua escola de algum debate sobre a situação dos negros no Brasil?

$39 \% \operatorname{Sim}$

$61 \%$ Não

8. Você acha que a situação dos negros no Brasil precisa ser discutida na escola? $94 \% \operatorname{Sim} 16 \%$ Não

9. Você já participou, na sua cidade, de alguma ação voltada para a reflexão sobre a situação dos negros no Brasil?

$15 \% \operatorname{Sim}$

$85 \%$ Não

10. Você acha necessário que sejam realizadas ações na sua cidade para fazer com que as pessoas façam uma reflexão sobre a situação dos negros no Brasil?

91\% Sim

$9 \%$ Não

Fonte: do Autor (2019), com base no Questionário do Apêndice A.

No que se refere à educação, por exemplo, o Estatuto da Igualdade Racial estabelece, como responsabilidade dos órgãos de ensino, providências no sentido de trazer, nas datas importantes para os negros, membros do movimento negro para debater com os estudantes acerca de suas vivências relativas ao tema em comemoração (Lei no $12.288,2010)$.

No tocante à cultura, tal ordenamento jurídico determina ao poder público o incentivo à celebração das personalidades e das datas comemorativas, relacionadas às manifestações culturais de matriz africana, tal como o samba, tanto em escolas públicas e como privadas (Lei oㅡ 12.288, 2010).

A "capoeira", por exemplo, é tratada no Estatuto da Igualdade Racial com grande destaque, sendo reconhecida como desporto de criação nacional (de matriz afro) e 
digna de incentivo e total proteção por parte do poder público, podendo, inclusive, ser ensinada nas instituições públicas e privadas (Lei no 12.288, 2010; Constituição Federal, 1988).

As informações da Tabela 4 revelam que $91 \%$ do alunos entrevistados conhecem a "capoeira", dos quais $61 \%$ concordam que ela seja considerada uma disciplina curricular a ser ensinada/praticada na escola. Porém é pouco provável que os alunos reconheçam na "capoeira" um dos elemento de combate ao racismo, exatamente por desconhecerem o seu real significado para a causa dos negros.

Tal ignorância provavelmente tem origem no desconhecimento do Estatuto da Igualdade Racial, de tal forma que muitos alunos não são capazes de estabelecer uma ligação entre a "capoeira" e o combate ao racismo no Brasil, esvaziando sua importância para a construção de uma nova identidade para os negros.

Tabela 4. Percentual de alunos que conhecem a "capoeira".

Perguntas 11, 12, e 13 do questionário do Apêndice $A$

11. Você sabe o que significa o esporte chamado "capoeira"?

$91 \% \operatorname{Sim}$

9\% Não

12. Se você sabe o que significa "capoeira", responda: você concorda que a "capoeira" faça parte do currículo escolar? (obs: se você não sabe o que é capoeira, não precisa responder).

\begin{tabular}{|l|l|l}
\hline $61 \% \operatorname{Sim}$ & $19 \%$ Não & $20 \%$ Indiferente
\end{tabular}

13. Se você não concorda que a "capoeira" faça parte do currículo escolar, responda: por que não concorda? (obs: se você não sabe o que é capoeira, não precisa responder).

15\% Capoeira é uma luta e não um esporte

$27 \%$ Capoeira é uma dança e não um esporte

15\% Capoeira é uma arte e não um esporte

$0 \%$ Na capoeira, há músicas que evocam espíritos

7\% A capoeira exige roupas específicas 
$21 \%$ Não gosto de capoeira

$15 \%$ Outro

\section{Fonte: do Autor (2019), com base no Questionário do Apêndice A.}

$\mathrm{Na}$ agenda das políticas públicas relacionadas com combate ao racismo, a reserva de vagas nas universidades e nos concursos públicos para afro-descendentes, foi o passo imediatamente seguinte à aprovação do Estatuto da Igualdade Racial (Lei $n^{\circ}$ 12.711, 2012; Lei n 12.990, 2014).

A Tabela 5 expõe uma forte tendência dos alunos entrevistados de não concordarem com tal política pública (56\%), muito provavelmente por causa da ausência de debates e de conhecimento dos benefícios que tais medidas têm trazido para a sociedade brasileira de uma forma geral e especificamente para a causa dos negros no Brasil (Mendes, 2017).

O fato é que tal tendência não deixa de ser uma manifestação do racismo não declarado e sutil que existe no Brasil, pois, apesar de condenarem o preconceito, os alunos, quando confrontados com situações comuns, do dia-a-dia, mostram-se preconceituosos (Mendes, 2017; Nunes, 2010).

Dos $56 \%$ que disseram não concordar com a política das cotas, a maioria justificouse citando a igualdade de todos perante a lei como ideal de justiça e a meritocracia como forma mais justa de seleção para acesso à universidade e concursos públicos. Mais uma vez, os alunos, sem perceber, expuseram um racismo velado, pois é impossível falar em igualdade numa realidade totalmente desigual e injusta para com os afro-descendentes brasileiros (Ferreira, 2007).

No que se refere ao mérito, muitas pessoas acreditam que qualquer processo de admissão que não tenha o mérito pessoal como critério primeiro é injusto, cabendo aos afro-descendentes vencerem pelas suas próprias capacidades (Ferreira, 2007).

Contudo, como argumenta Ferreira et al. (2007), tal conceito parece ignorar o fato de que as condições históricas dos negros, ao longo dos anos, têm produzido e 
reproduzido a pobreza, colocando-os em condição de desvantagem para competir com os demais.

Tabela 5. Percentual de opiniões sobre as cotas raciais em universidades e concursos públicos.

Perguntas 14 e 15 do questionário do Apêndice $A$

14. Você concorda que os negros tenham vagas reservadas (exclusivas) para ingresso nas universidades e em qualquer concurso público?

\section{\begin{tabular}{l|l}
$44 \% \operatorname{Sim}$ & $56 \%$ Não
\end{tabular}}

15. Se você não concorda que os negros tenham vagas reservadas para ingresso nas universidades e concursos públicos, responda: por que não concorda?

$39 \%$ Eu não concordo, pois todos são iguais perante a lei

$9 \%$ Eu não concordo, pois se trata de um preconceito com as demais raças

$2 \%$ Eu não concordo, pois as pessoas que não são negras não têm culpa de não terem nascidas assim

$39 \%$ Eu não concordo, pois as vagas devem ser ocupadas por mérito e não por causa da cor da pele

$11 \%$ Outro

Fonte: do Autor (2019), com base no Questionário do Apêndice A.

$\mathrm{Na}$ sequência das perguntas feitas aos alunos e em complemento aos dados especificados na Tabela 2, que trata da existência de racismo no Brasil, os alunos foram convidados a apresentarem propostas para combater o preconceito racial no Brasil.

Agrupadas por semelhança, de forma a estabelecer padrões de respostas (Vieira, 2010), as propostas mostraram que a educação foi considerada como o principal caminho para erradicar o racismo, seguida da conscientização pessoal/sociedade. Salvo erro, duas ações que guardam estreita relação entre si, pois, segundo alguns autores, a educação contribui para a formação de uma consciência crítica acerca da realidade, dos fatos e do próprio "eu" (Agostini, 2018). 
Em terceiro lugar, depois da educação e conscientização, os alunos apontaram, como solução, a necessidade de leis mais severas e de punições exemplares, como pena de morte e prisão perpétua, em concordância com o resultado de pesquisas semelhantes, como a realizada por Santos (2015).

Com isso, é perfeitamente possível concluir que, na concepção dos alunos, a punição tem papel importante na educação das pessoas, ou pelo menos possui caráter inibitório para condutas erradas. Muito provavelmente, tal pensamento representa o reflexo marcante das regras de sociabilização da família, através das quais os alunos foram educados, aceitando, como natural, a punição como uma boa forma de correção de condutas inapropriadas (Claro et al., 2017).

$\mathrm{Na}$ quarta colocação, apareceu o aspecto "respeito para com o próximo", algo que também possui relação com a educação. Entretanto, apesar de vincularem o preconceito à falta de educação, consciência e respeito, grande parte dos entrevistados parece transferir a responsabilidade para terceiros (governo, sociedade, etc.), não falando de si próprios, como se estivessem imunes a esse mal (Santos, 2015).

Tabela 6. Percentual das propostas de medidas contra o preconceito racial.

Pergunta 16 do questionário do Apêndice $A$

Se você acha que existe preconceito racial contra os negros no Brasil, e não aprova tal preconceito, que medida você acha que o governo e/ou a sociedade poderiam tomar para mudar essa situação?

1. Lei(s) mais severa(s) 32 alunos

2. Melhorar o ensino (educação) 38 alunos

3. Punição 25 alunos

4. Respeito com o próximo 18 alunos

5. Conscientização pessoal/sociedade 34 alunos

6. Nunca será mudado 3 alunos

7. Não existir classificação por cor da pele 3 alunos 
8. Ser uma disciplina do currículo escolar 1 aluno

9. Mais oportunidade para os negros 6 alunos

10. Ocorreu no passado, mas não existe preconceito atualmente 1 aluno 11. Denunciar para as autoridades 3 alunos

Fonte: do Autor (2019), com base no artigo escrito por Santos (2015).

Uma das grandes barreiras para erradicar o preconceito é, indubitavelmente, a dificuldade dos afro-descendentes assumirem suas raízes, isto porque, em uma sociedade em que a normalidade é ser branco, como a brasileira, o distanciamento do padrão significa ser considerado anormal e, portanto, condenado a viver à margem da sociedade (Fernandes et al., 2016).

No entanto, os números exibidos pelo Instituto Nacional de Estudos e Pesquisas Educacionais (INPE), no Caderno de Estudos e Pesquisas em Políticas Educacionais, acerca do acesso às universidades públicas, mostram que o universo de autodeclarados afro-descendentes vem aumentando consideravelmente a cada ano (INPE, 2018). Alguns especialistas confirmam essa tendência, atribuindo tal avanço às políticas afirmativas do Governo Federal (Silveira, 2019).

A Tabela 7 revela que, dos 192 alunos entrevistados, mais de 50\% declarou-se branco, ainda que a cara típica do brasileiro seja amorenada, conforme pesquisas recentes que indicam um número maior de miscigenados do que de brancos no Brasil (Silveira, 2019).

Apesar do número de pessoas que se declaram afro-descendentes ter crescido significativamente, muitos ainda relutam em fazê-lo, sendo perfeitamente provável que, entre os alunos entrevistados, haja aqueles que ainda não assumiram suas raízes e se declararam brancos, mesmo não sendo. No entanto, não se pode ignorar os aspectos da colonização do estado de São Paulo, que, entre os estados da federação, foi o que mais imigrantes europeus recebeu no século XIX, sobretudo o interior (IBGE, 2007). 
Todavia algo que é digno de nota é o fato de 10 alunos renunciarem à classificação "morena" (mais popular e menos polarizada, segundo o IBGE) para se declararem "pardos", numa demonstração de vitória sobre os conceitos e "pré-conceitos" sociais e pessoais (IBGE, 2013).

Tabela 7. Quantidade de alunos segundo a corda pele.

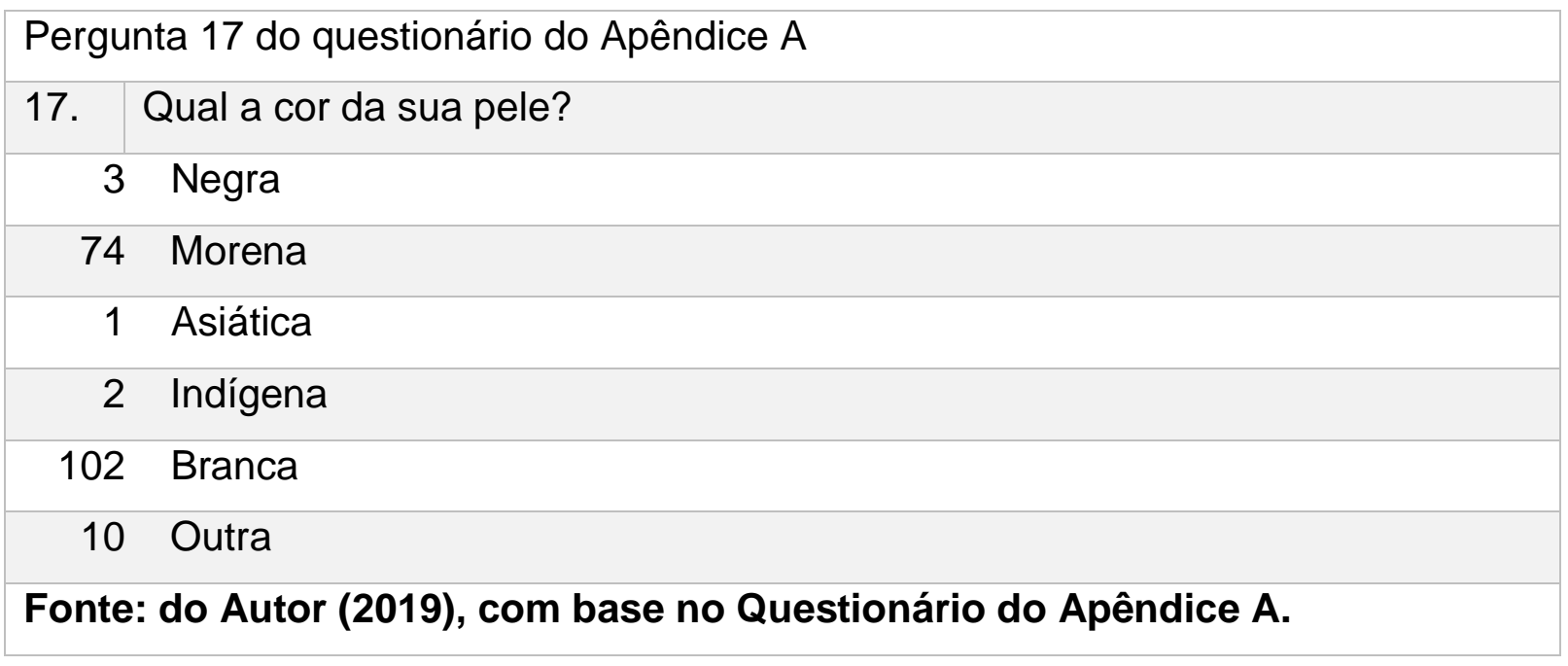

\section{CONCLUSÕES}

Os resultados obtidos através das análises do questionário aplicado revelam que a solução para erradicar o preconceito está na educação; todavia, grande parcela dos alunos parece desconhecer as políticas públicas voltadas para erradicá-lo, como é o caso da Lei das Cotas que é desconhecida por $44 \%$ dos alunos entrevistados. O mais triste dessa realidade é que o desconhecimento está presente justamente entre os maiores interessados nesse dispositivo legal (os alunos do ensino médio), que estão prestes a concorrerem a uma vaga no ensino superior.

Tanto escola quanto município da região de Itapetininga parecem não ter compreendido com perfeição o significado e a importância das ações afirmativas, culturais e educativas, no combate ao racismo, pois parcela significativa dos alunos entrevistados jamais participou de ações do gênero no ambiente educacional e social. 
Tal verdade parece confirmar-se com a recusa da Diretoria de Ensino da Região de Itapetininga em permitir a realização desta pesquisa no âmbito escolar, ainda que: (1) não houvesse custo de qualquer natureza para o Estado, (2) pudesse ser realizada fora do horário de aula, e (3) não demandasse a participação de professores.

Os dados mostraram que o racismo é uma realidade bem presente na sociedade brasileira, pois além de todos os alunos conhecerem-no, mais de 70\% afirmaram ter presenciado situação qualificada como racista. No entanto, ainda que reconheçam a existência de preconceito racial no Brasil, mais da metade foi contra o sistema de cotas raciais para acesso à universidade e para os concursos públicos, o que pode ser um indicativo de um racismo não declarado, resultante, muito provavelmente, da ausência de ações afirmativas culturais e educativas na região.

Os debates, por certo, teriam dado aos alunos maiores condições de entenderem o que significa racismo "não declarado" e quais são as dimensões em que o preconceito racial se manifesta (ideológica, prática e estrutural), permitindo-lhes aumentar o rol de situações de racismo presenciadas e fazendo-lhes aceitar com maior facilidade e apoiar as ações afirmativas para combater algo tão cruel como o preconceito racial (Campos, 2017).

O breve censo realizado na pesquisa mostrou que a maioria dos alunos considera-se branco, o que não representa um absurdo, pois o Estado de São Paulo foi o maior destino dos imigrantes europeus no século XIX. Todavia é bem provável que haja, entre os alunos, aqueles que sentem vergonha de se declarar afro-decente, algo muito comum numa sociedade pouco motivada para desenvolver ações que permitam às pessoas vencer a dificuldade de assumirem-se como não brancas.

A verdade é que nenhuma política pública do governo federal será bem sucedida se não houver o empenho das autoridades executoras e que estão mais próximas dos alunos (instituições de ensino e autoridades do poder público estadual e municipal), tornando vão todo o esforço empreendido pelo poder público federal na busca de formar uma nova identidade para os afro-descendentes no Brasil. 
Perdem com isso a sociedade como um todo e, principalmente, os alunos que acabam por não desenvolver o senso crítico acerca de questões atuais e fundamentais da sociedade brasileira, tendendo a reproduzirem os modelos anteriores, altamente preconceituosos, de forma a propagar a ideia ilusória de que o Brasil vive uma democracia racial.

\section{REFERÊNCIAS}

AGOSTINI, Nilo. Conscientização e Educação: ação e reflexão que transformam o mundo. Revista Pro-posições, Campinas, v.29, n. 3, p. 187-206, set./dez. 2017.

BRASIL. Constituição (1988). Constituição da República Federativa do Brasil. Brasília, DF: Senado Federal: Centro Gráfico, 1988.

BRASIL. Lei n 9.394, de 20 de dezembro de 1996. Diário Oficial [da] União, Poder Executivo, Brasília, DF, 23 dez. 1996. p. 27833.

BRASIL. Lei ํo11.645, de 10 de março de 2008. Diário Oficial [da] União, Poder Executivo, Brasília, DF, 11 mar. 2008. Seção 1, p. 1.

BRASIL. Lei no 12.288, de 20 de julho de 2010. Diário Oficial [da] União, Poder Executivo, Brasília, DF, 21 jul. 2012. Seção 1, p. 1.

BRASIL. Lei o 12.711, de 29 de agosto de 2012. Diário Oficial [da] União, Poder Executivo, Brasília, DF, 30 ago. 2012. Seção 1, p. 1.

BRASIL. Lei no 12.990, de 9 de junho de 2014. Diário Oficial [da] União, Poder Executivo, Brasília, DF, 10 jun. 2014. Seção 1, p. 3.

CAMPOS, L.A. Racismo em três dimensões: uma abordagem realista-crítica. Revista Brasileira de Ciências Sociais, São Paulo, v. 32, n. 95, p. 1-19, 2017.

CERVO, A.L.; BERVIAN, P.A. Metodologia científica (3. ed.). São Paulo: McGrawHill, 1983. 
CHEMIM, M.S.A. O negro no espaço escolar. In: Os desafios da escola pública paranaense na perspectiva do professor. Ponta Grossa: Secretaria de Estado da Educação, $2013, \quad$ p. $\quad 4-25 . \quad$ Disponível em: $<$ http://www.diaadiaeducacao.pr.gov.br/portals/cadernospde/pdebusca/producoes_p de/2013/2013_uepg_hist_pdp_maria_do_socorro_chemim.pdf>. Acesso em 12 nov. 2019.

CLARO, A.L.A; RIBEIRO, C.S.S. Educar ou punir? um olhar sobre os atos de indisciplina. 2017. Trabalho apresentado no XII Congresso Nacional de Educação, Curitiba, 2017.

FERNANDES, V.B.; SOUZA, M.C.C.C. Identidade Negra entre exclusão e liberdade. Revista do Instituto de Estudos Brasileiros, São Paulo, n. 63, p. 103-120, abr. 2016.

FERREIRA, R.F; MATTOS, R.M. O Afro-Brasileiro e o Debate Sobre o Sistema de Cotas: Um Enfoque Psicossocial. Psicologia, Ciência e Profissão, Brasília, v. 27, n. 1, p. 46-63, 2007.

GOVERNO DO ESTADO DE SÃO PAULO. Diretoria de Ensino - Região de Itapetininga. 2019. Diponível em: <https://deitapetininga.educacao.sp.gov.br/>. Acesso em 12 nov. 2019.

GUARNIERI, F.G.; MEL-SILVA, L.L. Cotas Universitárias no Brasil: Análise de uma década de produção científica. Psicologia Escolar e Educacional, São Paulo, v. 21 , n. 2, p. 183-193, mai./ago. 2017.

HENKEL, K. A categorização e a validação das respostas abertas em surveys políticos. Opinião Pública, Campinas, v. 23, n. 3, p. 786-807, set./dez., 2017.

INSTITUTO BRASILEIRO DE GEOGRAFIA E ESTATÍSTICA (IBGE). Brasil 500 anos de povoamento. Rio de Janeiro: IBGE, 2007. Disponível em: < https://biblioteca.ibge.gov.br/visualizacao/livros/liv6687.pdf>. Acesso em 28 nov. 2019. 
INSTITUTO BRASILEIRO DE GEOGRAFIA E ESTATÍSTICA (IBGE). Características étnico-raciais da população: classificações e identidades. Rio de Janeiro: IBGE, 2013. Disponível em: <https://biblioteca.ibge.gov.br/visualizacao/livros/liv63405.pdf>. Acesso em 12 nov. 2019.

INSTITUTO NACIONAL DE ESTUDOS E PESQUISAS EDUCACIONAIS (INEP). Caderno de estudos e e pesquisas em políticas educacionais. Ministério da Educação, Brasília, DF, 2018. Disponível em: < http://portal.inep.gov.br/informacaoda-publicacao/-/asset_publisher/6JYIsGMAMkW1/document/id/5047099>. Acesso em 26 nov. 2019.

MARTINS, Júlio. Metodologia da pesquisa científica. Praia Grande: Alfamérica Faculdade, 2017.

MEDEIROS, Carlos Augusto. Estatística aplicada à educação. Brasília: Universidade de Brasília, 2007.

MELLO, Daniel. Mais de um terço dos domicílios brasileiros não tem acesso à internet. Empresa Brasileira de Comunicação, Brasília, DF, 2018. Disponível em: < http://agenciabrasil.ebc.com.br/geral/noticia/2018-07/mais-de-um-terco-dosdomicilios-brasileiros-nao-tem-acesso-internet>. Acesso em: 26 nov. 2019.

NUNES, S.S. Racismo contra negros: um estudo sobre o preconceito sutil. 2010. Tese (Doutorado em psicologia)-Instituto de Psicologia da Universidade de São Paulo, São Paulo, 2010.

RIBEIRO, S.M.; ALMEIDA, M.T.C.; MAIA, F.A.; SOUZA, F.A.; AMARAL, D.P.O.; ALVES, M.R. Política de cotas no ensino superior: percepções de professores e estudantes. Revista Unimontes Científica, Montes Claros, v. 18, n.1 - jan./jun. 2016.

SALES JUNIOR, R. Democracia racial: o não-dito racista. Revista de Sociologia da USP, São Paulo, v. 18, n. 2, p. 229-258, 2006. 
SANSONE, L. Pais Negros, Filhos Pretos. Trabalho, cor, diferença entre gerações e o sistema de classificação racial num Brasil em transformação. In: Negritude sem etnicidade: o local e o global nas relações raciais e na produção cultural negra do Brasil [online]. Salvador: EDUFBA, 2003, pp. 38-87. Disponível em: <http://books.scielo.org/id/cqtc4/pdf/sansone-9788523211974-02.pdf>. Acesso em 12 nov. 2019.

SANTOS, G.A. Nem crime, nem castigo: o racismo na percepção do judiciário e das vítimas de atos de discriminação. Revista do Instituto de Estudos Brasileiros, São Paulo, n. 62, p. 184-207, dez. 2015.

SILVA, L.G.M; FERREIRA, T.J. O papel da escola e suas demandas sociais. Periódico Científico Projeção e Docência, Taguatinga, DF, v. 5, n. 2, dez. 2014.

SILVEIRA, Daniel. Em sete anos, aumenta em $32 \%$ a população que se declara preta no Brasil. Portal de Notícias G1, Economia, Rio de janeiro. 2019. Disponível em: < https://g1.globo.com/economia/noticia/2019/05/22/em-sete-anos-aumenta-em32percent-a-populacao-que-se-declara-preta-no-brasil.ghtml>. Acesso em: 28 nov. 2019.

VIEIRA, J.G.S. Metodologia de pesquisa científica na prática. Curitiba: Fael Editora, 2010.

\section{APÊNDICE}

A - Questionário.

\section{Questões}

Nome:

Idade:

Escola onde estuda:

Ano escolar em que se encontra: ( ) Primeiro （ ) Segundo （）Terceiro Data: 
1. Você já ouviu falar na "Lei das Cotas" para negros?
( ) Sim
( ) Não

2. Se você já ouviu falar na "Lei das Cotas" para negros, responda: onde ouviu falar? (obs: caso não tenha ouvido falar, não marque nenhuma resposta)

( )TV ( )Escola ( )Entre amigos ( )Internet ( )Revistas/Jornais ( )Evento

( ) Outro:

3. Se você já ouviu falar na "Lei das Cotas" para negros, responda: sabe o que ela significa? (obs: se nunca ouviu falar, não marque nenhuma resposta).
( ) Sim
( ) Não

4. Você sabe o que significa "racismo" (preconceito racial contra os negros)?
( ) Sim
( ) Não

5. Você acha que existe "racismo" atualmente no Brasil?
( ) Sim
( ) Não

6. Você já presenciou alguma situação que chamaria de "racismo"?
( ) Sim
( ) Não

7. Você já participou na sua escola de algum debate sobre a situação dos negros no Brasil?
( ) Sim
( ) Não

8. Você acha que a situação dos negros no Brasil precisa ser discutida na escola?
( ) Sim
( ) Não

9. Você já participou, na sua cidade, de alguma ação voltada para a reflexão sobre a situação dos negros no Brasil?
( ) Sim
( ) Não

10. Você acha necessário que sejam realizadas ações na sua cidade para fazer com que as pessoas façam uma reflexão sobre a situação dos negros no Brasil?
( ) Sim
( ) Não

11. Você sabe o que significa o esporte chamado "capoeira"?
( ) $\operatorname{Sim}$
( ) Não 
12. Se você sabe o que significa "capoeira", responda: você concorda que a "capoeira" faça parte do currículo escolar? (obs: se você não sabe o que é capoeira, não precisa responder).

( ) Sim ( ) Não ( ) Indiferente

13. Se você não concorda que a "capoeira" faça parte do currículo escolar, responda: por que não concorda? (obs: se você não sabe o que é capoeira, não precisa responder).

( ) Capoeira é uma luta e não um esporte

( ) Capoeira é uma dança e não um esporte

( ) Capoeira é uma arte e não um esporte

( ) Na capoeira, há músicas que evocam espíritos

( ) A capoeira exige roupas específicas

( ) Não gosto de capoeira

( ) Outro:

14. Você concorda que os negros tenham vagas reservadas (exclusivas) para ingresso nas universidades e em qualquer concurso público?

( ) Sim ( ) Não

15. Se você não concorda que os negros tenham vagas reservadas para ingresso nas universidades e concursos públicos, responda: por que não concorda?

( ) Eu não concordo, pois todos são iguais perante a lei

( ) Eu não concordo, pois se trata de um preconceito com as demais raças

( ) Eu não concordo, pois as pessoas que não são negras não têm culpa de não terem nascidas assim

( ) Eu não concordo, pois as vagas devem ser ocupadas por mérito e não por causa da cor da pele

16. Se você acha que existe preconceito racial contra os negros no Brasil, e não aprova tal preconceito, que medida você acha que o governo e/ou a sociedade poderiam tomar para mudar essa situação? 
17. Qual a cor da sua pele?

( ) Negra

( ) Morena

( ) Asiática

( ) Indígena

( ) Branca

( ) Outra:

Fonte: do Autor (2019), com base no Estatuto da Igualdade Racial (Lei n. 12.288, 2010).

Enviado: Dezembro, 2019.

Aprovado: Janeiro, 2020. 